\title{
Water Monitoring and Automatic Feed in Aquarium Based on Microcontroller
}

\author{
Mochammad Haldi Widianto, Aris Darisman,
}

\begin{abstract}
Automatic technology needs to be applied to all items that are still not fully automated. But in reality still not all automation tools implement all parts working automatically. As with maintaining fish in an aquarium which is a hobby of urban residents who work manually and routinely, such as feeding fish regularly then monitoring $\mathrm{pH}$, etc., therefore transferring the work of caring for fish and aquariums is important to be done automatically. Using a microcontroller and other sensors combined into an integrated system can automate activities such as raising fish in an aquarium. Automatic activities include monitoring the $\mathrm{pH}$ of water and feed supplemented with reports in the form of SMS as information for aquarium owners. By using an automatic water and fish feed monitoring system based on a microcontroller, aquarium owners can find out the $\mathrm{pH}$ value of aquarium water even though they know how to calculate it and will feel calm when traveling for a long time because the aquarium has been automated, where the bait will be given automatically according to the schedule and predetermined portion. The formation of tools using the waterfall method commonly used to design technology so that research is expected to know the impact of the formation of this waterfall. Microcontroller results are tested using a black box to measure the original size with the size of the results of the microcontroller. the results show that if this automation is done using the waterfall method and tested using a black box successfully produces automation in the aquarium. .
\end{abstract}

Keywords : Microcontroller, Aquarium Water $p H$ Measurement, Automatic Feed..

\section{INTRODUCTION}

$\mathrm{T}_{0}$ oday's technological advancements have an impact on the manufacture of sophisticated all-round technology to facilitate all human activities. Automatic technology is in great demand by everyone, so many people have begun to implement automation in everything that was previously manual. Not only are basic needs being automated, hobby needs have also begun to be automated. Keeping fish in an aquarium is a hobby that is completely manual, ranging from feeding, monitoring aquarium water, monitoring the condition of the fish, changing water and so on. Despite consuming time and energy every day, many people like to

Revised Manuscript Received on December 30, 2019.

* Correspondence Author

Mochammad Haldi Widianto*, Informatics, School of Creative Technology Binus Bandung, Bandung, Indoneisa. Email: mochamad.widianto@binus.ac.id

Aris Darisman, Visual Communication Design, School of Creative Technology Binus Bandung, Bandung, Indonesia, Email: arisdarisman@binus.edu

(C) The Authors. Published by Blue Eyes Intelligence Engineering and Sciences Publication (BEIESP). This is an open access article under the CC BY-NC-ND license (http://creativecommons.org/licenses/by-nc-nd/4.0/) keep fish in an aquarium as a hobby and as a decoration of the house, it is necessary to provide artificial food [1]

According to research [2], in helping to improve the performance of fish water quality in the aquarium and the availability of feed and also fish food is very important. Very low water $\mathrm{pH}$ or if less than 5.0 is the cause of mucus lumps in fish so that fish in the aquarium will suffocate, on the other hand, a very high $\mathrm{pH}$ or maybe higher than 9.0 will cause fish not to eat a long time. And food feed is one of the supporters in fish breeding, where the main function of fish food is for survival and growth. So that research is carried out to provide adequate, timely and sustainable food and meet nutritional and digestive requirements, it is necessary to provide artificial food [3].

Therefore, the function of water control and feeding must be good and right [4]. Problems that arise and often occur are when the owner or keeper of fish in the aquarium must leave the house for a long time. From these problems, we need a technology that can help fish hobbyists can still care for their favorite fish even though the hobbyist is far outside the house. A device that can monitor water conditions and feed fish in an aquarium.

\section{SYSTEM MODEL}

\section{A. Monitoring System}

A system has a definition that is a group of elements that are related to each other, which function together to achieve the specified goals. according to [3] the system is a collection/group of sub-systems/parts/ components of any physical or non-physical that are interconnected with one another and work together in harmony to achieve a certain goal. Monitoring is the act of gathering information with minimum effort to decide promptly. The information that has been collected can be used for later analysis, discussion, and reporting. Monitoring allows us to monitor the process routinely within a certain period of time, determine whether a process has been going well or in accordance with the original purpose [4]. The monitoring system is a collection of components that are mutually related and have their respective functions in collecting information on an object being monitored, then the information is conveyed to the person conducting the monitoring [4].

Artificial feed or so-called pellets contain enough vitamins to meet the nutritional needs of fish [5].

Table I: Nutrient content

\begin{tabular}{|c|c|}
\hline \multicolumn{1}{|c|}{ Ingredients } & AKG \\
\hline Protein & $30 \%$ \\
\hline Fat & $3 \%$ \\
\hline
\end{tabular}




\begin{tabular}{|c|c|}
\hline Fiber & $4 \%$ \\
\hline Ash & $12 \%$ \\
\hline Water content & $12 \%$ \\
\hline
\end{tabular}

some of the ingredients used in this research are:

- Microcontroller

- Analog Water PH sensor kit

- Buzzer

- Motor Servo

- RTC (Real-time clock)

\section{B. Method of collecting data}

Data collection is the process or action taken by someone to get the information or data needed. There are several ways you can do to collect data, including the following:

- Literature Study

A literature study according to [6] that is looking for data that has been documented. Documentation, from the origin of the word document, which means written items such as books, laws and regulations, scientific work, and so on.

- Observation

According to [6] Observation has a definition of direct observation, observation is usually used in ways such as tests, questionnaires, various images, and sound recordings.

- Interview

According to [6] Interview has a definition that is a meeting between two or more people to exchange existing information or ideas through question and answer so that they can build meaning in a particular topic with interviews,

\section{Design Method}

In system design, this method is a framework that is used as if it were compiling, planning, and controlling the process of designing a system itself. Many working systems have been developed so far, each of which has its strengths and weaknesses. Some examples of system design methods available include waterfall, prototyping, incremental, spiral.

The waterfall method is often referred to as the classic life cycle, where it implies a systematic approach to software development and also several other projects related to software, starting with the specification of user needs and then continuing through the analysis phase (analysis ), design (design), coding (code)), and testing (test)[7].

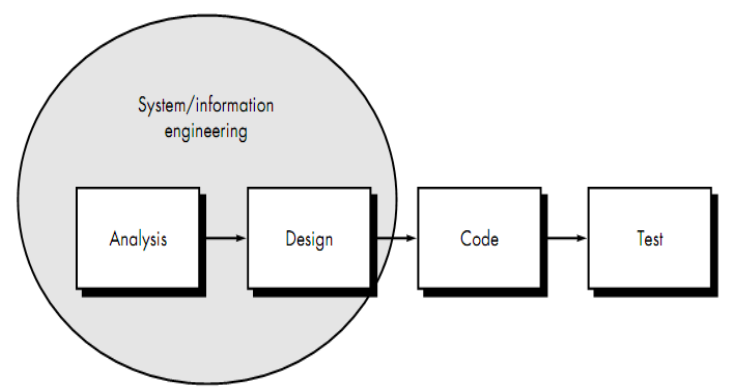

Fig 1 Waterfall Method

\section{Testing}

Testing is the final stage of making a system or tool. testing is done to ensure the system or tool is made to function properly as planned. Some keywords in software testing can be considered [8], [9]

\section{Dynamic}

- Ultrasonic sensor

Software testing is carried out at various inputs. This input is determined before testing is carried out with limitations that are tailored to the capabilities of the software. Input does not have to be possible for further use of the program, but rather encompasses all the limitations that can be reached by the software and random sampling for the testing process.

\section{Limited}

Although testing is done on simple software so that it is complicated though, testing is done by meeting certain limitations in accordance with the capabilities of the program. This limitation also applies to the entries selected for testing. Not all input possibilities are tested in the software because it will take quite a long time considering so many possibilities that can occur. To overcome this, a random selection of inputs to the testing process that is expected to meet the needs of software testing will be carried out.

\section{Certain}

The test is carried out with certain limitations tailored to expectations on the function, response, and characteristics of the software. These limits will be adjusted according to existing testing techniques. The selection of the most appropriate testing criteria is complex. In practice, analysis of testing risks and experience with similar tests will be required.

\section{Hope}

This keyword has the expected conditions, both in the form of a system response to the input and the response characteristics. In this case, the limits of the expected test results must be determined. Thus, it can be seen whether the software has met the expected test results or requires a revamping, both in the form of repairs and software development.

\section{DESIGN MODEL}

Based on a series of analyzes and information searches that have been carried out, it can be concluded that each fish owner or hobbyist provides fish feed twice a day, morning and evening. For the portion given is adjusted to the needs. And for monitoring water use the $\mathrm{PH}$ value as a parameter for aquarium water quality.

Taking into account the above analysis, the microcontroller is made by having 3 basic functions, namely issuing feed automatically at a predetermined time every day, monitoring the $\mathrm{pH}$ of the water to ensure water hardness in accordance with the needs of fish in the aquarium, and SMS notification and notification sound (alarm).

At the design stage is divided into four stages, namely hardware design, feed dispensing tank design, microcontroller case design, and a series of modules. Hardware design is made to determine the modules to be used. The output design of the feed is made so that the portion of the feed that is released is as desired. The case design is made portable so that this tool can be used in aquariums with a water capacity of 50 - 1000 liters of water. And the module circuit design is made to connect several modules to the microcontroller 


\section{A. Hadware Design}

The microcontroller will connect other parts such as LCD, RTC which will control the servo motor to open the valve, after that the GSM component will send a message so that nothing is left behind.

Besides that, the microcontroller serves as the center of the imaging system above. accuracy in working is still influenced by the microcontroller itself

\section{B. Tank Design and Feed Removal}

Tank Design and Feeding Expenditures. For explanation as follows.

1. Feed tank cover, made of soft rubber foam to protect feed from water and air.

2. Ultrasonic installed at the bottom of the lid.

3. The tube is used to hold feed, made from $0.5 \mathrm{~mm}$ thick Acrylic Mica

4. Top cushion, made of soft rubber foam which serves to hold the feed in the tank so it does not come out when the feed spinner ejects the feed.

5. Screws, used to install the feed spinner on the servo.

6. Feed spinner, made from soft rubber foam with a circular shape and there is a hole used to take feed in the tank and remove feed by rotating to an angle of 0 (position just below the top bearing) so that the feed in the tube does not enter the feed spinner hole.

7. Cover the bottom of the tank, used to hold the position of the servo motor so that it can spin the feed spinner. The bottom lid of the tank also has a horizontal position of the top bearing of the feed so the feed in the feed spinner can come out.

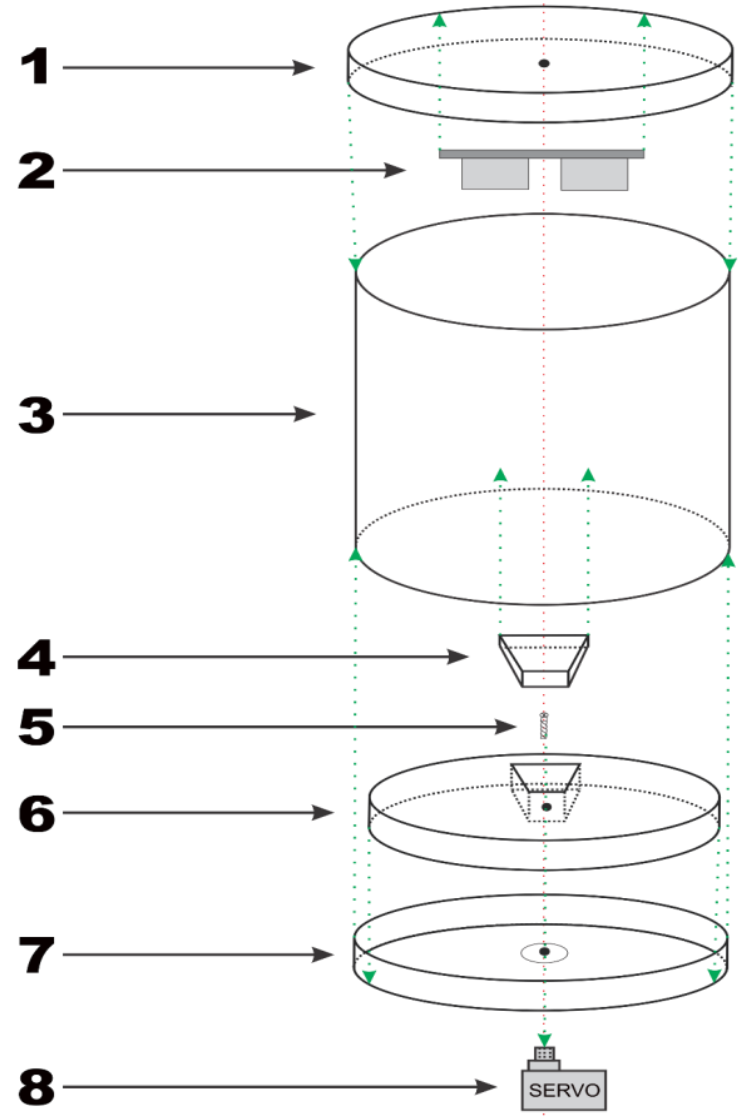

Fig 3. Tube Design and Feed Discharge
For an explanation of Fig 3 the Case Design of a Microcontroller is as follows.

1. Feed tank, $1 / 4$ the bottom tank is put in a box.

2. GSM antennas are stored outside the acrylic box for easy signal reception.

3. The GSM module is stored in a transparent acrylic box to be able to see the notification lights from the module.

4. The acrylic box is made transparent so that each module that has a notification light can be seen.

5. The LCD is stored in a transparent box to protect it from aquarium water splashes.

6. Electric socket is connected to AC current.

7. Made from an aquarium water filter box, so that the device can be portable and can be opened and installed in several aquariums.

8. Feed pipe.

9. The $\mathrm{pH}$ meter sensor is dipped ( $50 \%$ the bottom of the sensor) into the aquarium water.

\section{Scripts Intruction}

The coding flow of this system is to repeat, see Figure 4 Microcontroller System Flow. If the value condition of all FALSE sensors will continue to repeat the appearance of the text on the LCD, but if there is one or all conditions of the TRUE value, the system will give notice in the form of writing on the LCD, notification sound (alarm), and SMS.

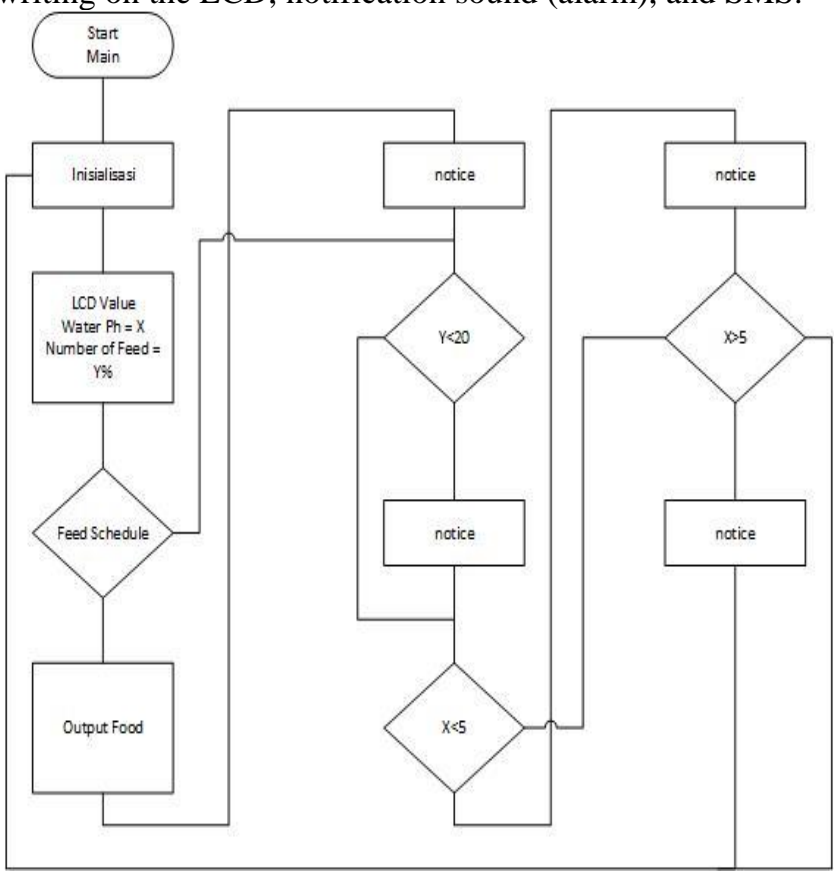

Fig 4. Microcontroller Instruction System Flowchart

\section{Comparison With Other Similar Automatic Systems}

According to monitoring and research carried reference [9] out on other similar automated systems, this microcontroller tool system has the advantage of a portion of the feed that is released consistently at each feed release because it uses a feed spinner hole to measure the released feed. In contrast to other automatic systems that use open and close the feed tube door provided by a timer or use a DC motor to remove feed. 
If you use open and close the tank door, even though the opening and closing times are the same, the amount of feed that comes out will not be the same because the pressure of the amount of feed in the tank can affect the speed of feed out so that the amount of feed that comes out will not be consistent. If the feed is full, the outgoing feed tends to be more, but if the feed in the tank decreases, the pressure decreases and the outgoing feed tends to be less. Likewise, with a DC motor, the amount of feed that comes out is also influenced by the amount of feed pressure in the tank.

Most other automatic systems release a large amount of feed and will not be eaten all by the fish in the aquarium causing the residual feed to settle. The rest of the food that settles will make the water turbid within a few hours and cause disease for fish. Other similar automatic systems are more suitable if used in ponds rather than aquariums.

In addition to using feed spinner, this microcontroller system also has a water $\mathrm{pH}$ measuring feature and a system report in the form of SMS. The automatic microcontroller tool system is made more recommended because it has many advantages compared to other automatic systems. This microcontroller system in addition to performing its main function (automatic feeding) also pays attention to water quality in the aquarium. Factors that can reduce the quality of water are excessive feed and residual dirt that has accumulated in the water filter. By using this microcontroller system has reduced 1 factor that affects the decrease in water quality (excessive feed).

\section{E. Waterfall mechanism}

The waterfall model is a method that was once widely used in several software manufacturers. This method takes several traditional approaches and is deemed less flexible than the new agile methodology. But for the experiments in this study, the waterfall model was used.

The Waterfall Model basically consists of seven consecutive phases [10]:

1. System requirements: the first relates to requirements that are highly related to the automation product itself but which are relevant to the microcontroller such as the availability of goods, pins, power, type of microcontroller..

2. Requirements analysis: The intended analysis aims to examine the functions of eligibility and other interests. The results of this phase are items of explanation that must be developed.

3. Program design: Technical design can now be implemented with the help of specifications. The results of program design are usually recorded in diagrams that illustrate the theoretical behavior of software.

4. Implementation: During the implementation period, the workflow is carried out by considering how the conditions and objectives of the framework. The design of the microcontroller in the software becomes a program that is directly related.

5. Testing: The implementation phase is carried out by testing all or some components of the microcontroller. Integration into the operating system can also be checked. If errors and conflicts occur, the system must be repaired immediately.

6. Launch: Microcontroller is implemented after considering several things. Updates and maintenance may be needed before the product enters the customer.

\section{F. Testing Black Box}

According to [8] there are types of software testing methods, viz.

1. White Box

White box testing is a test that is carried out by checking in full the design details, using a procedural control structure and then testing again based on how a software produces output from the input. But this test must be carried out by people who have the competence and knowledge of QA (Quality Assurance)

\section{Black Box}

Black box testing is more testing the functional specifications. This test is usually used to determine the device whether the functions, inputs, and outputs of the software meet the required specifications. Black box testing is done by making a test case. The test case in question is to build around specifications and requirements, that is, what applications should be carried out. Use an external description of the software, including specifications, requirements, and design to derive test cases. This test can be functional or non-functional, although it is usually functional.

Based on the description above, the testing conducted for this microcontroller system uses the black box testing method. Because the black box testing method can be tested by the microcontroller system maker without having to involve people who have QA competence

\section{RESULT}

To use the product from the microcontroller, we just plug it in or plug in the edges of the aquarium and connect the adapter to the power socket. The microcontroller tool system is easy to install, making it easier to install. Example of installing a microcontroller tool system in Fig 5. Using a Microcontroller Tool System in an Aquarium.

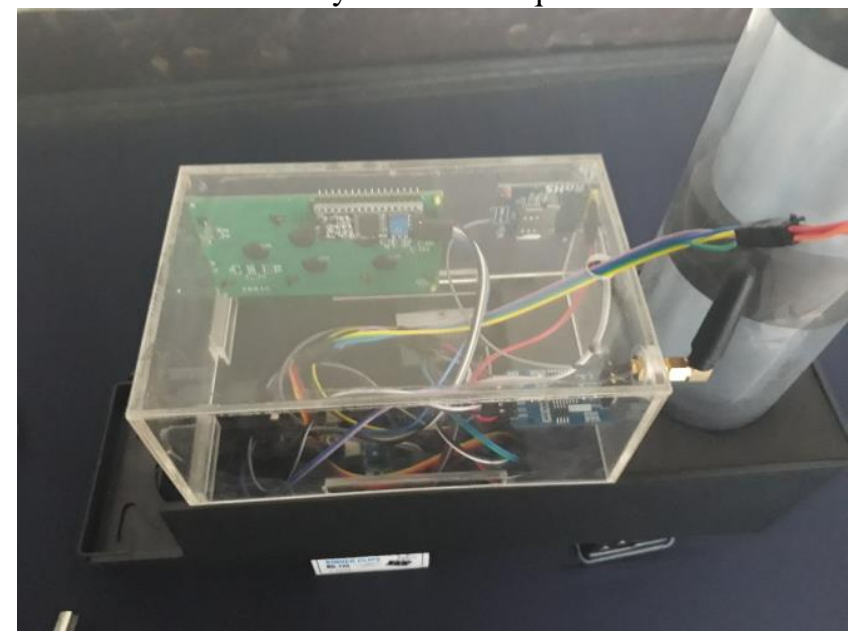

Fig 5. Use of Microcontroller System Tools in Aquariums

\section{A. Timeliness In Microcontroller Device Systems}

When testing finished goods, , it is done by using the time difference between the microcontroller and real time using the blackbox method as a test. Blackbox test result data is displayed at

\section{Published By:} Eyes Intelligence Engineering \& Sciences Publication 
Table II Time Trial Results.

\begin{tabular}{|c|c|c|c|}
\hline Day & $\begin{array}{l}\text { Microcontroller } \\
\text { Time } \\
\end{array}$ & Real Time & $\begin{array}{c}\begin{array}{c}\text { Black Box } \\
\text { Result }\end{array} \\
\end{array}$ \\
\hline \multirow{2}{*}{1} & 07:00:00 & 07:00:00 & Successful \\
\hline & 19:00:00 & 19:00:00 & Successful \\
\hline \multirow{2}{*}{2} & 07:00:00 & 07:00:00 & Successful \\
\hline & 19:00:00 & 19:00:00 & Successful \\
\hline
\end{tabular}

According to the results of testing the timeliness and prove [9]. the microcontroller system that has been carried out there is compatibility with real time.

\section{B. Accuracy of Feeding on Schedule}

Furthermore, black box also for feed testing will be carried out to ensure the microcontroller tool system releases food according to the specified schedule. The test result data is shown in Table II Feed Expenditure Test Results on Schedule.

Table III. Trial Result for Feed Expenditures

\begin{tabular}{|c|c|c|c|}
\hline Day & $\begin{array}{c}\text { Feed Expense } \\
\text { Schedule }\end{array}$ & Food Out & $\begin{array}{c}\text { Black Box } \\
\text { Result }\end{array}$ \\
\hline \multirow{2}{*}{1} & $08: 00$ & Yes & Successful \\
\cline { 2 - 4 } & $20: 00$ & Yes & Successful \\
\hline \multirow{2}{*}{2} & $08: 00$ & Yes & Successful \\
\cline { 2 - 4 } & $20: 00$ & Yes & Successful \\
\hline
\end{tabular}

According to the results of testing and prove [8] the accuracy of feeding according to the schedule that has been done, there is conformity with the specified instructions.

\section{Accuracy in Water PH Measurement}

\section{Table IV. Test Results for the Accuracy of Water PH} Measurement

\begin{tabular}{|c|c|c|}
\hline Measured pH value & $\begin{array}{c}\text { PH Measurement } \\
\text { Results By } \\
\text { Microcontroller }\end{array}$ & $\begin{array}{c}\text { Black Box } \\
\text { Result }\end{array}$ \\
\hline $\mathrm{pH} \mathrm{5,00}$ & 5,02 & Successful \\
\hline $\mathrm{pH} \mathrm{7,06}$ & 7,06 & Successful \\
\hline
\end{tabular}

According to the results [8] what has been done is no difference. When the measurement of water temperature can affect the $\mathrm{pH}$ value of the water being measured using blackbox testing, the results show a slight difference occurs, this is because the water temperature can change to adjust the temperature in the surrounding environment.

\section{Advantage and disadvantage Waterfall Methods}

After automating using a microcontroller we get the advantages of the waterfall method [10] such as:

- Because the structure of the algorithm is logical, conceptual errors can often be avoided.

- This model is indeed directed at things that focus on extensive technical documentation, which makes it easy for programmers to create new developer models and are also useful in the testing phase.

- The progress of the automation project can be monitored using milestones.

Last disadvamtage of the waterfall methods such as:

- Conflicts, bugs, cookies, errors and some program errors sometimes cause increased funding and considerable time.
- Specifications whose intentions were originally made are often difficult for consumers to understand because they are less clear than something a software should do.

\section{CONCLUSION}

Based on research, design, and manufacture of microcontroller tool systems that have been carried out and development using the waterfall method, some conclusions can be drawn including the following. Feeding fish in the aquarium should be done routinely and regularly, which often inhibits the hobbyist of fish freely moving outside the home. Then Using an automated system can help fish enthusiasts travel freely even for long periods without worrying that the fish in their aquarium will starve to death. This has been resolved by using a microcontroller and has been tested using blackbox testing. Automatic tool system that uses the waterfall method has a dose of adequate feeding so that there will be no excess feed that can make the aquarium turbid water and cause a source of germs on fish. Finally, it was determined that using the waterfall method was useful for this study because it was proven after testing using a blackbox. but there are still some shortcomings. So it is possible to use other methods in the future.

\section{REFERENCES}

1. K. N. Hairol, R. Adnan, A. M. Samad, and F. Ahmat Ruslan, "Aquaculture Monitoring System using Arduino Mega for Automated Fish Pond System Application," Proc. - 2018 IEEE Conf Syst. Process Control. ICSPC 2018, no. December, pp. 218-223, 2019.

2. R. Aisuwarya and E. F. Suhendra, "Development of Automatic Fish Feeding System based on Gasping Behavior," 2018 Int. Conf. Inf. Technol. Syst. Innov. ICITSI 2018 - Proc., pp. 470-473, 2019.

3. S. Panic, H. Milosevic, S. Vasic, and V. Milenkovic, "Dynamical characteristics of the FSO transmission capacity in the presence of Rician turbulence," 2018 Int. Conf. Inf. Commun. Technol. ICOIACT 2018, vol. 2018-Janua, pp. 769-772, 2018.

4. I. S. Akila, P. Karthikeyan, H. M. V. Hari, and K. J. Hari, "IoT Based Domestic Fish Feeder," Proc. 2nd Int. Conf. Electron. Commun. Aerosp. Technol. ICECA 2018, no. Iceca, pp. 1306-1311, 2018.

5. O. U. R. Promise, "Service Menu," pp. 1-8, 2012.

6. M. A. Zhuohao, "A study on the teaching of English and American literature based on computer network," Proc. - 2016 Int. Conf. Robot. Intell. Syst. ICRIS 2016, pp. 67-70, 2016.

7. Z. Sun, "A waterfall model for knowledge management and experience management," Proc. - HIS'04 4th Int. Conf. Hybrid Intell. Syst., pp. 472-475, 2005.

8. F. Song, Z. Zhou, S. Li, Y. En, and B. Li, "failure data for space TWT accelerated life test," pp. 1112-1115, 2014.

9. S. S. Barhate, "Effective test strategy for testing automotive software," 2015 Int. Conf. Ind. Instrum. Control. ICIC 2015, no. Icic, pp. 645-649, 2015.

10. N. Mukai, Y. Sakai, and Y. Chang, "Waterfall simulation by using a particle and grid-based hybrid approach," Proc. - 2014 Int. Conf. Cyberworlds, CW 2014, pp. 23-30, 2014.

\section{AUTHORS PROFILE}

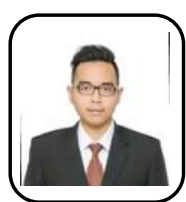

Mochammad Haldi Widianto is a lecturer at the Bandung Binus Creative Technology school. He obtained a bachelor's degree in Telecommunications and a master's degree in Telecommunications from Telkom University. Before becoming a lecturer, he was a technician at LIPI as well as a consultant at the Indonesian KOMINFO ministry. He has handled various problems at KOMINFO, especially at the Monitoring Center and resolved them as a consultant. 
In the field of education he has conducted research in various fields, especially in the field of telecommunications networks. His teaching experience for undergraduate students is in the fields of biostatistics, neural networks, mathematical modeling and signal processing. Now he is based in Bandung and resides there

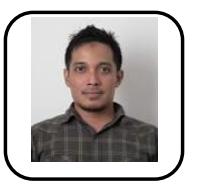

Aris Darisman, S.Sn., M.Ds. He completed his undergraduate education at the Faculty of Fine Arts and Design - ITB, in 1994-1999. In 2012 - 2014 he continued his Masters of design studies at Trisakti University in Jakarta. He became a teaching assistant at the Faculty of Art and Design from 2000-2003, then in 2003-2006 he taught at the National Institute of Technology (ITENAS), in basic design education. In 2007 he taught at Binus University in the Visual Communication Design study program. Subjects taught: Character Design, Drawing, Illustration Design. In 2017 I was transferred to BINUS @Bandung, and held the position of Head of the Visual Communication Design Program.. He teaching experience for undergraduate student in design topics 